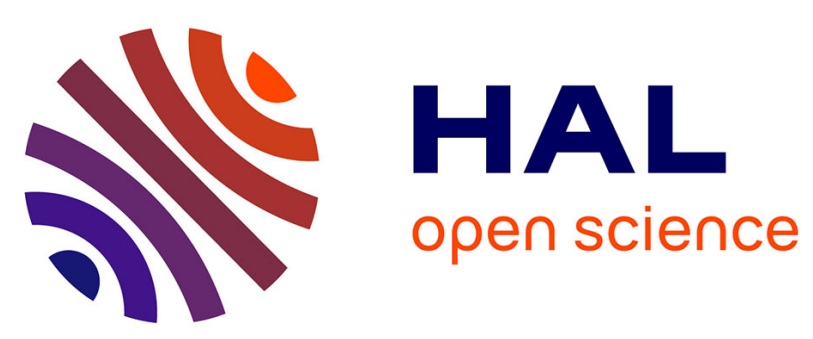

\title{
Impacts of Human Body on Antenna Radiation in Indoor Environments: Numerical Modeling and Experimental Validation
}

Zaher Sayegh, Mohamed Latrach, Fumie Costen, Ghaïs El Zein, Gheorghe Zaharia

\section{To cite this version:}

Zaher Sayegh, Mohamed Latrach, Fumie Costen, Ghaïs El Zein, Gheorghe Zaharia. Impacts of Human Body on Antenna Radiation in Indoor Environments: Numerical Modeling and Experimental Validation. International Symposium on Signals, Circuits and Systems, Jul 2013, Iasi, Romania. pp.1-4. hal-00873928

\section{HAL Id: hal-00873928 \\ https://hal.science/hal-00873928}

Submitted on 16 Oct 2013

HAL is a multi-disciplinary open access archive for the deposit and dissemination of scientific research documents, whether they are published or not. The documents may come from teaching and research institutions in France or abroad, or from public or private research centers.
L'archive ouverte pluridisciplinaire HAL, est destinée au dépôt et à la diffusion de documents scientifiques de niveau recherche, publiés ou non, émanant des établissements d'enseignement et de recherche français ou étrangers, des laboratoires publics ou privés. 


\title{
Impacts of Human Body on Antenna Radiation in Indoor Environments : Numerical Modeling and Experimental Validation
}

\author{
Zaher Sayegh ${ }^{1,3}$, Mohamed Latrach ${ }^{1}$, Fumie Costen ${ }^{2}$, Ghais El Zein ${ }^{3}$, Gheorghe Zaharia ${ }^{3}$ \\ ${ }^{1}$ ESEO, Radio \& Microwave Team, 10 Bd Jeanneteau - CS 90717, 49107 Angers Cedex 2, France \\ ${ }^{2}$ School of Electric and Electrical Engineering, University of Manchester, U.K. \\ ${ }^{3}$ IETR-INSA de Rennes, Rennes, France \\ zaher.sayegh@eseo.fr
}

\begin{abstract}
The presence of human body has an important influence on the wireless communication systems in indoor environments. The need of efficient prediction for such coverage becomes essential. This paper present an efficient electromagnetic indoor propagation modeling, taking into account the presence of human body and the nature of materials of the complex environment, based on the Finite-Difference Time-Domain method. Numerical results are compared with measurement results and show a good agreement.
\end{abstract}

\section{INTRODUCTION}

Efficiency and accuracy are more and more required in wireless propagation modeling in indoor environments for planning better coverage. This coverage is influenced by the geometry and material characteristics of existing obstacles in the environment.

A code based on the FDTD (3D) method has been developed with FORTRAN and adapted to our context of study taking into account the presence of obstacles and their properties (the presence of human was not considered in the code). It allows obtaining interesting results in agreement with measurements [1]-[12].

In this paper we are looking to predict the radiation of CMA 118/A omnidirectional antenna at $2.4 \mathrm{GHz}$ in presence and absence of human body placed in a room $(48 \lambda \times 18 \lambda \times 20 \lambda)$ as presented in Figure 1, in presence and absence of human body. The code was enhanced to take into account the presence of human body in the environment, numerical results are compared with measurement results, a good agreement is obtained.
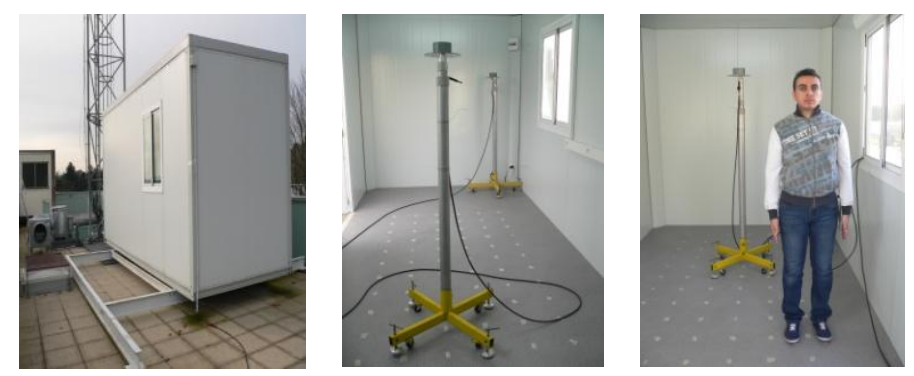

Figure 1. Scenario of study

\section{SCENARIO AND MEASUREMENTS}

We choose an empty steel room (Figure 2), measuring $6.06 \mathrm{x}$ $2.3 \times 2.5 \mathrm{~m}^{3}$ containing a metallic heater and two glass windows, two omnidirectional "Conical Monopole Antennas" CMA-118/A (1-18 GHz) are used for this scenario, one "Network Analyzer" HP - 8753D (30 KHZ - $6 \mathrm{GHz}$ ), two coaxial cables $(5 \mathrm{~m})$, a computer to control the measurement configuration and calibration and data transfer. The network analyser and the computer were outside the room. The frequency band used is $2.3-2.5 \mathrm{GHz}$ (401 points), the transmitting power is $8 \mathrm{dBm}$.
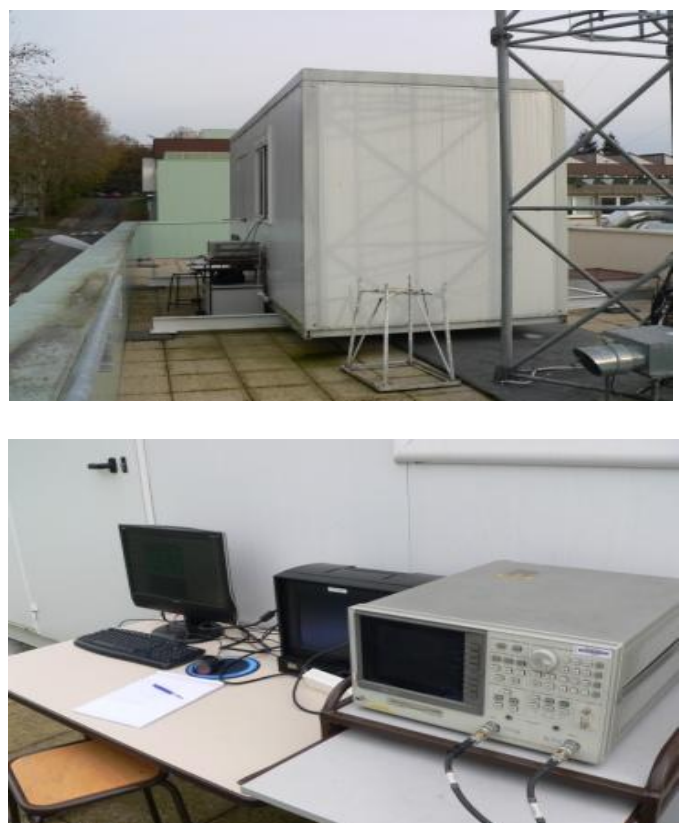

Figure 2. Measurement materials

\section{A. First Measurements - Antenna height $H=1.64 \mathrm{~m}$}

In the first measurements, the transmitting and receiving antennas are placed $164 \mathrm{~cm}$ above the floor level in the empty room. 
The repartition of radiated power measured for 108 positions separated by $2 \lambda$ is represented in Figure 3 ; the red cross represent the transmitter position.

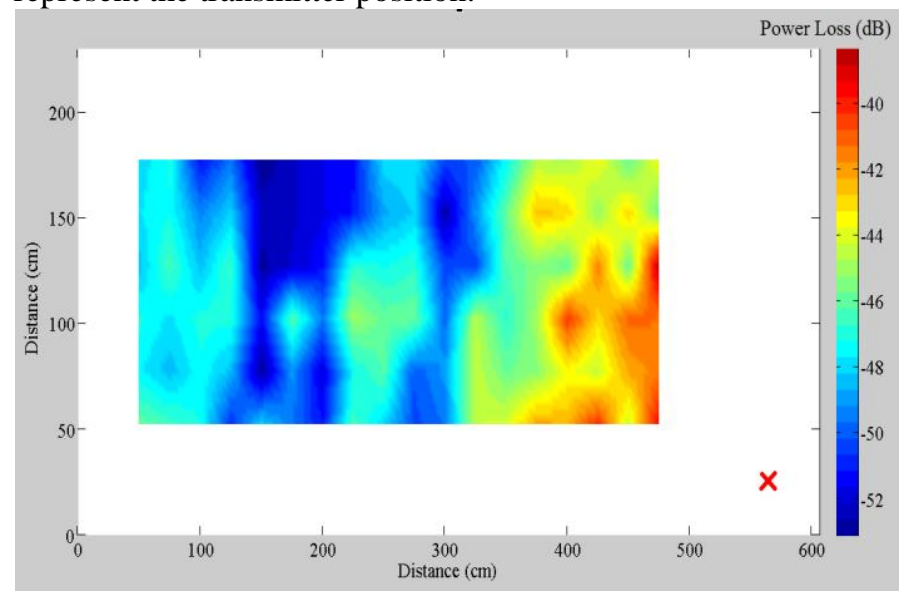

Figure 3. Power Loss (dB) measured at $1.64 \mathrm{~m}$

\section{B. Second Measurements - Antenna height $H=1.8 m$}

In the second measurements, the transmitting and receiving antennas are placed $180 \mathrm{~cm}$ above the floor level in the empty room.

The repartition of radiated power measured for 108 positions separated by $2 \lambda$ is represented in Figure 4; the red cross represent the transmitter position.

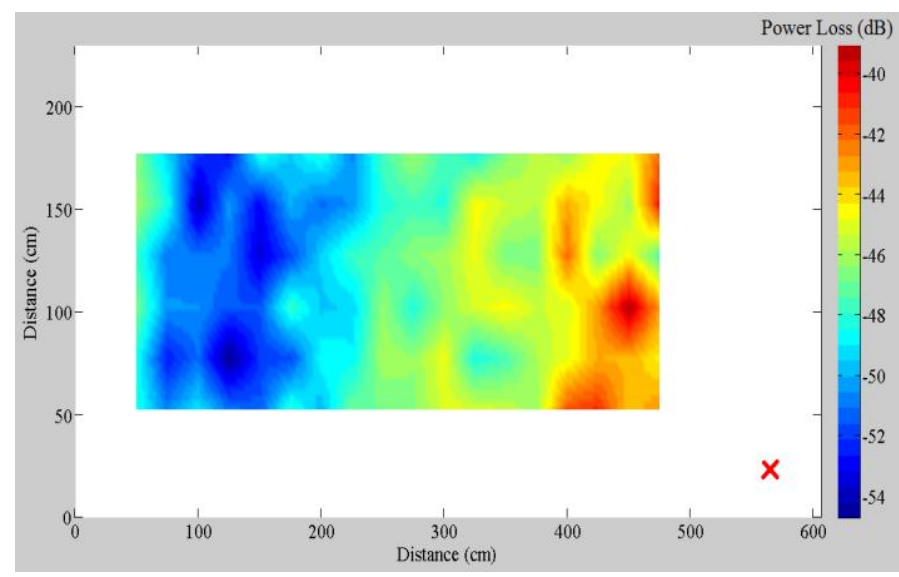

Figure 4. Power Loss $(\mathrm{dB})$ measured at $1.8 \mathrm{~m}$

\section{Third Measurements - Presence of human body $(H=1.8 m)$}

In the third measurements, the transmitting and receiving antennas are placed $180 \mathrm{~cm}$ above the floor level in presence of human body.

The repartition of radiated power measured for 108 positions separated by $2 \lambda$ is represented in Figure 5 , the red cross represent the transmitter position and the gray rectangle represent the human body position.

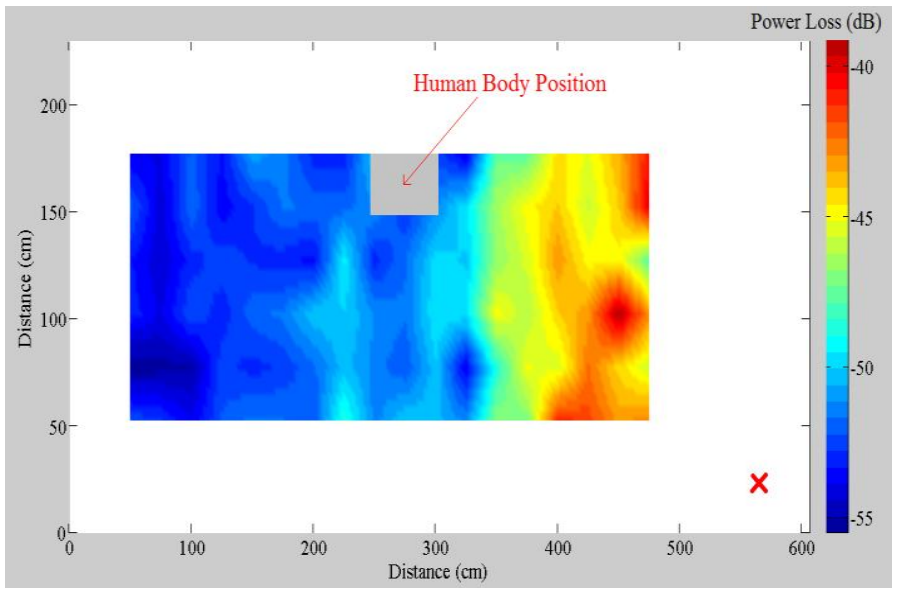

Figure 5. Power Loss $(\mathrm{dB})$ measured in presence of human body at $1.8 \mathrm{~m}$

\section{MODELING WITH FDTD CODE}

We create the scenario by FDTD code as shown in Figure 6. We start by defining the scenario's geometry (walls, floor, ceiling, windows ...). Then we define the materials (conductivity and permittivity). We can add more furniture inside the environment.

We define the frequency $(2.4 \mathrm{GHz}$ in our study), the spatial step (we choose $\lambda / 10$ to get a good accuracy or $\lambda$ is the wavelength) and the transmitting point(s) source(s) location(s).

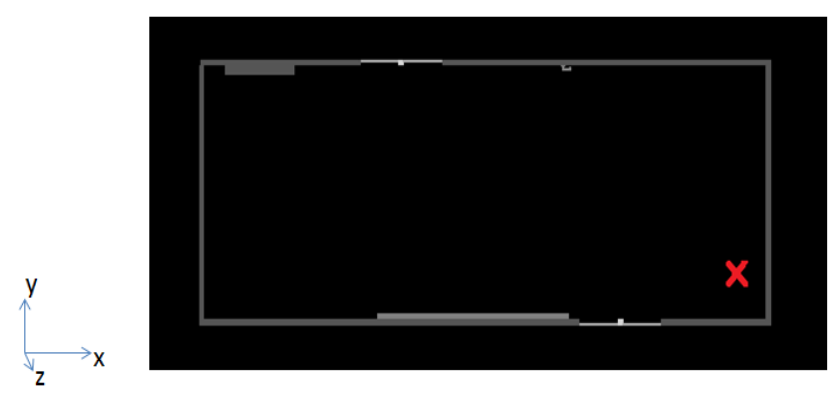

Figure 6. Scenario defined by FDTD code

The FDTD code has a capability to produce the electric field and the magnetic field in time domain at any location in the defined environment. We use the Fourier transform to get the electromagnetic fields in frequency domain and extract the values of electric and magnetic fields at $2.4 \mathrm{GHz}$ in order to compute the Poynting vector $\mathrm{P}=|\mathrm{E} \times \mathrm{H}|[13]$

$$
\begin{aligned}
P=( & {\left[\left(E_{y} \cdot H_{z}\right)-\left(E_{z} \cdot H_{y}\right)\right]^{2}+\left[\left(E_{z} \cdot H_{x}\right)-\left(E_{x} \cdot H_{z}\right)\right]^{2} } \\
+ & {\left.\left[\left(E_{x} \cdot H_{y}\right)-\left(E_{y} \cdot H_{x}\right)\right]^{2}\right)^{1 / 2}\left(W / m^{2}\right) }
\end{aligned}
$$



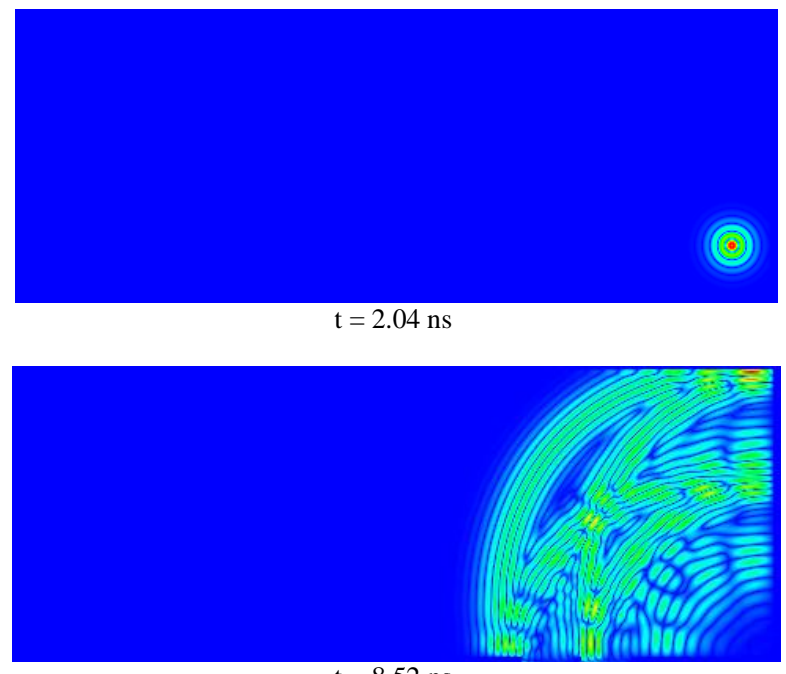

$\mathrm{t}=8.52 \mathrm{~ns}$
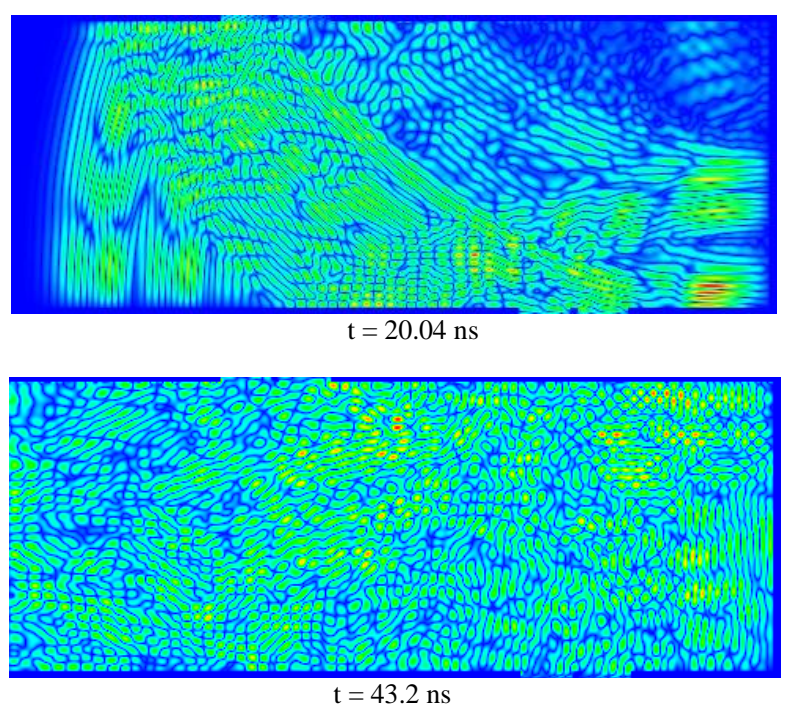

Figure 7. Electromagnetic waves propagation in time domain (FDTD code)

Figure 7 shows how electromagnetic waves propagate inside the room taking into account all significant physical phenomena like signal reflection, absorption, penetration, diffraction and diffuse scattering.

The current version of the FDTD code has a capability to handle the output data that we need and also the number of processors for the computation and we are able to add human body inside the defined environment (geometry and material properties of human body).

Three simulations are done in order to compare with measurements. For the first simulation, the source location is at $\mathrm{z}=1.64 \mathrm{~m}$. The repartition of radiated power computed for 108 positions separated by $2 \lambda$ is represented in Figure 8 ; the red cross represent the transmitter position.

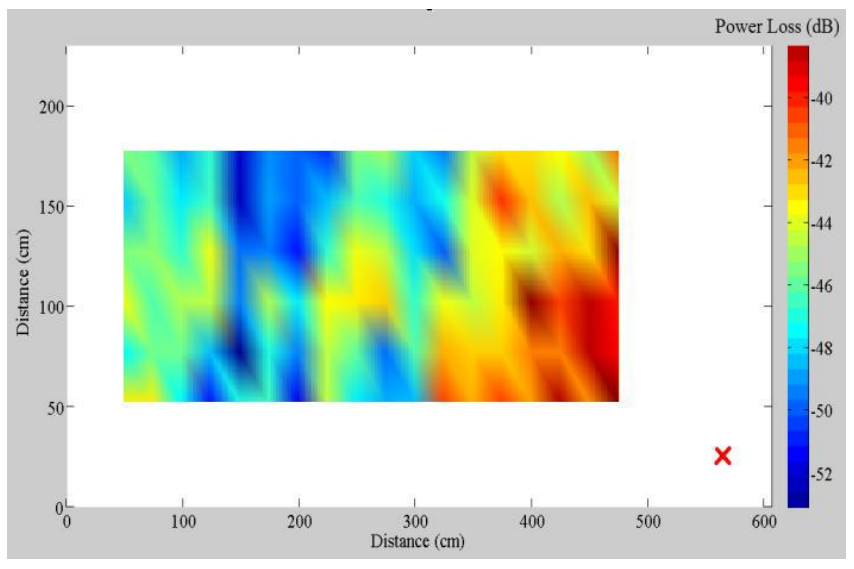

Figure 8. Power Loss $(\mathrm{dB})$ computed by FDTD code at $1.64 \mathrm{~m}$

For the second simulation, the source location is at $\mathrm{z}=1.8 \mathrm{~m}$. The repartition of radiated power computed for 108 positions separated by $2 \lambda$ is represented in Figure 9; the red cross represent the transmitter position.

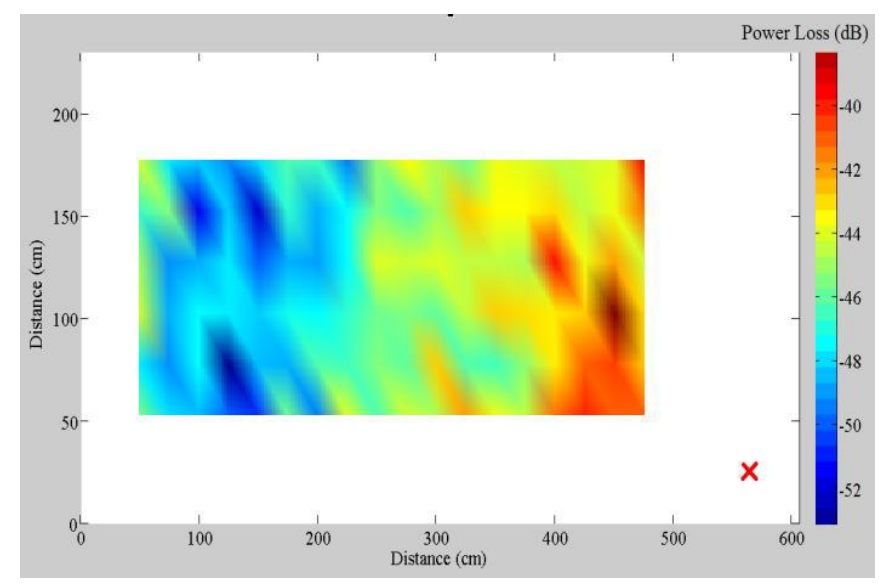

Figure 9. Power Loss (dB) computed by FDTD code at $1.8 \mathrm{~m}$

The third simulation includes the human body at the same position of measurements with source location at $1.8 \mathrm{~m}$. The repartition of radiated power computed for 108 positions separated by $2 \lambda$ is represented in Figure 10; the red cross represent the transmitter position.

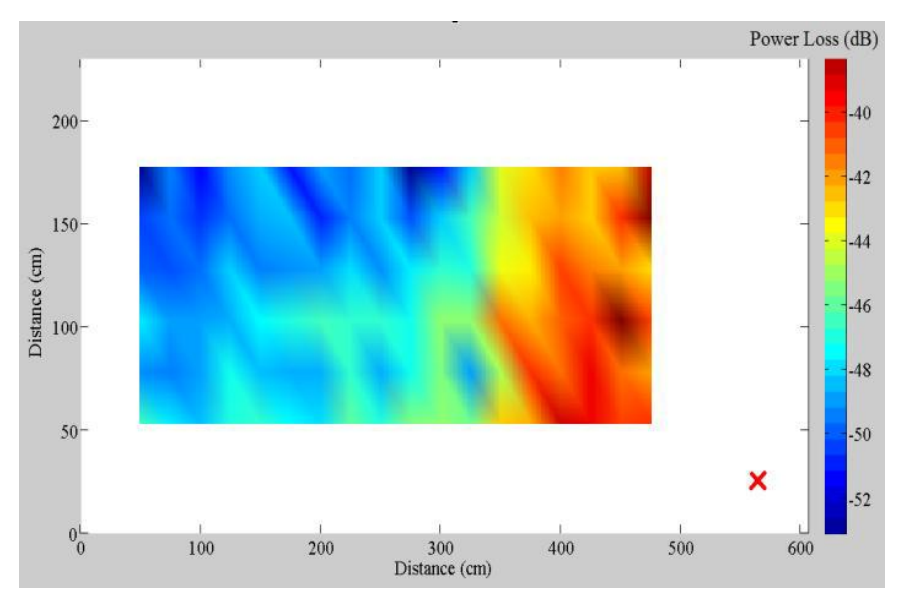

Figure 10. Power Loss (dB) computed in presence of human body 


\section{COMPARISON BETWEEN SIMULATION AND MEASUREMENTS}

Numerical results are compared with measurement results as shown in figure 11.

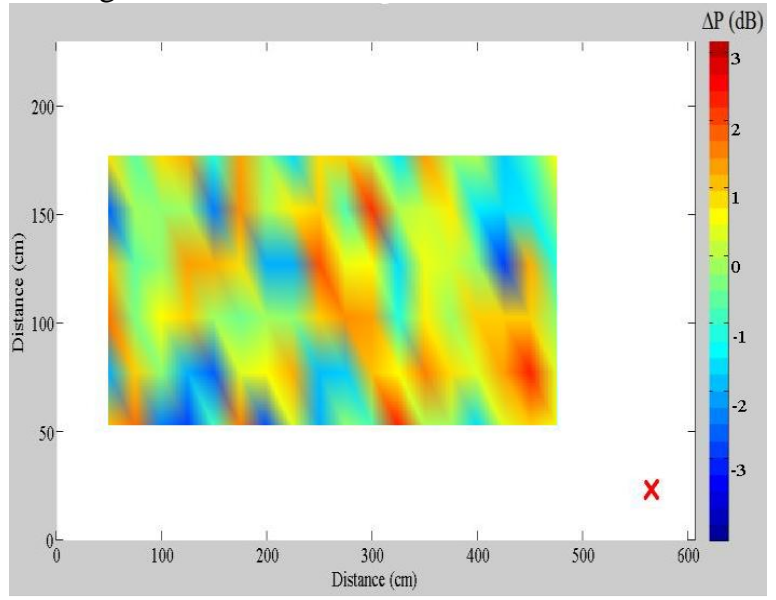

(a)

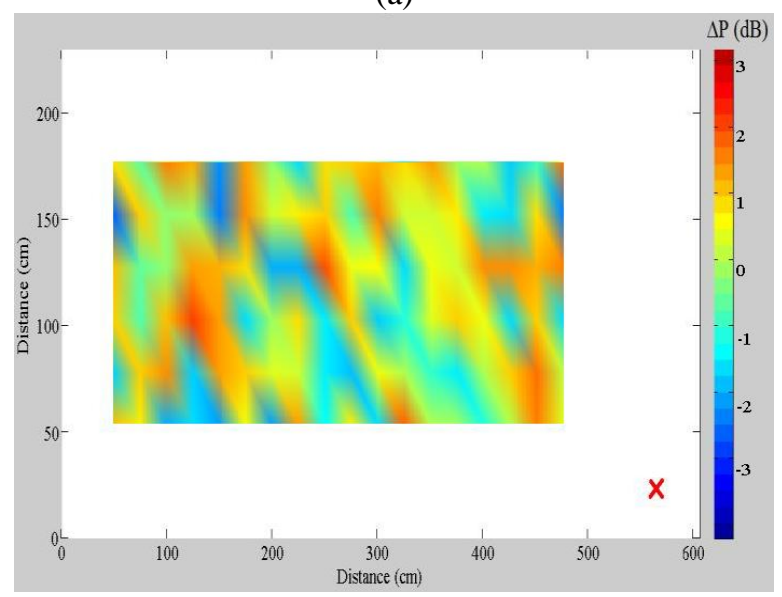

(b)

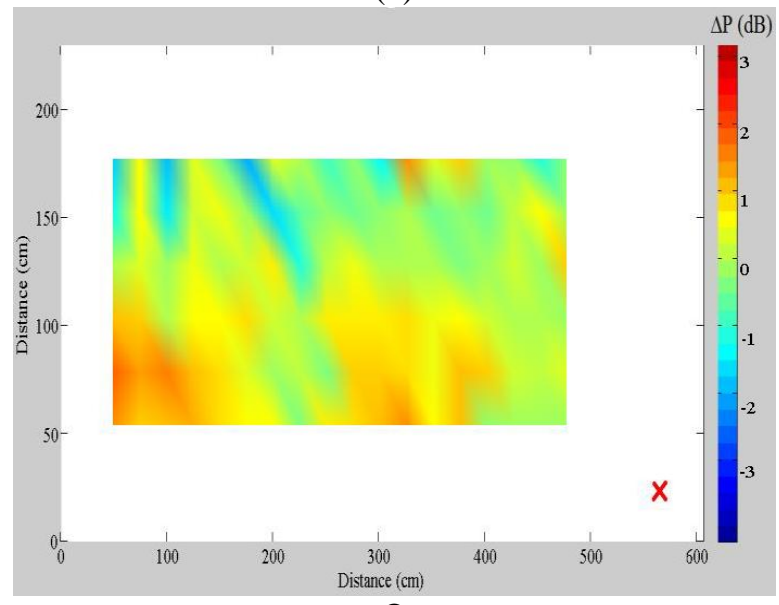

(C)

Figure 11. Difference of radiated power $(\mathrm{dB})$ between measurements and simulations (a) for empty room at $1.64 \mathrm{~m}$ (b)for empty room at $1.8 \mathrm{~m}$ (c) in presence of human body

The difference between the measurements results and the simulations results can be seen between -3 and $3 \mathrm{~dB}$.
This little difference shows the capacity of the FDTD code to modeling indoor electromagnetic propagation.

We used for these simulations, one computer which has 8 processors and 32 GB of RAM. The computation time for each study was about 31 minutes, using 8 processors and $3.9 \mathrm{~GB}$ of RAM.

\section{CONCLUSION}

An efficient electromagnetic indoor propagation modeling based on the 3D FDTD method is enhanced and presented in this paper taking into account the presence of human body.

Numerical results are presented and compared with measurements to validate the capability of our code to modeling electromagnetic propagation for indoor environments.

The characteristics of antenna should be integrated in the FDTD code in the future to get more accuracy.

\section{REFERENCES}

[1] Z. Sayegh, M. Latrach, F. Costen, W. Abdouni, G. El Zein and G. Zaharia, "Antenna Radiation in Typical Office Environment: Theoretical Modeling and Measurements”, EMS 2012, Malta 14-16 November 2012.

[2] Allen Taflove, Susan C. Hagness, Computational Electrodynamics: The finite-difference time-domain method, Artech House, Norwood, 2005.

[3] Yee K, "Numerical Solution of Initial Boundary Value Problems Involving Maxwell's Equations in Isotropic Media”, IEEE Trans. Ant. Prop., vol. 33, May 1966, pp.302-307.

[4] Taflove A and Brodwin M, "Numerical solution of steady state electromagnetic scattering problems using the time dependent Maxwell's equations”, IEEE MTT, vol. 23, no. 1, Aug. 1975, pp. 623-630.

[5] D Sheen, S Ali, M Abouzahra, and J Kong, "Application of ThreeDimensional Finite-Difference Method to the Analysis of Planar Microstrip Circuits”, IEEE MTT, vol. 38, pp. 849-57, Jul 1990.

[6] X Zang, J Fang and K Mei, "Calculations of the dispersive characteristics of microstrips by the FDTD method", IEEE MTT, vol. 26, pp. 263-267, Feb. 1988.

[7] Railton C and McGeehan, "Analysis of microstrip discontinuities using the FDTD method", MWSYM 1989, pp. 1089-1012.

[8] Shibata T, Havashi T and Kimura T, "Analysis of microstrips circuits using three-dimensional full-wave electromagnetic field analysis in the time-domain", IEEE MTT, vol. 36, pp. 1064-1070, Jun. 1988.

[9] Feix N, Lalande M and Jecko B, "Harmonically Characterization of a Microstrip Bend via the FDTD Method", IEE Proceedings, IEEE MTT, vol. 40, no. 5, May 1992, pp. 955-961.

[10] A Taflove, "The Finite-Difference Time-Domain Method for Electromagnetic Scattering and Interaction Problems", IEEE Trans. Electromagnetic Compatibility, vol. EMC-22, pp. 191-202, Aug. 1980.

[11] Railton CJ, Richardson KM, McGeehan JP and Elder KF, "The Prediction of Radiation Levels from Printed Circuit Boards by means of the FDTD Method", IEE International Conference on Computation in Electromagnetics, Savoy Place, London, Nov. 1991.

[12] WJ Buchanan, NK Gupta, "Prediction of Electric Fields from Conductors on a PCB by 3D Finite-Difference Time-Domain Method", IEE's Engineering, Science and Education Journal, Aug. 1995.

[13] P. Neeakanta, T. Kishkan, R. Chaterjee, "Antennas for Information Super Skyways: An Exposition on Outdoor and Indoor Wireless Antennas", Research Studies Press Ltd, pp. 223, $1^{\text {st }}$ edition (December 1, 2002). 